\title{
The effects of combined catalysis of oxalic acid and seawater on the kinetics of xylose and arabinose dehydration to furfural
}

\author{
Wijittra Hongsiri · Bart Danon · Wiebren de Jong
}

Received: 1 July 2014/ Accepted: 17 October 2014/Published online: 12 November 2014

(C) The Author(s) 2014. This article is published with open access at Springerlink.com

\begin{abstract}
It is known that both acids and salts have a positive catalytic effect on the dehydration of pentoses to form furfural, a potentially attractive platform chemical. In this study the effects of the combined usage of an organic acid, instead of stronger mineral acids, and a saline catalyst is investigated. In order to assess these effects, the kinetics of pentose dehydration to furfural are studied using oxalic acid as the primary catalyst and $\mathrm{NaCl}$ or seawater as the secondary saline catalyst. The interactions between these two types of catalysts are complex and are, therefore, also assessed thermodynamically. The addition of salts lowers the activity coefficient of the hydronium ions, but simultaneously favours the dissociation of the organic acid. It turned out that these two effects are of similar magnitude, resulting in a fairly constant hydronium ion activity. Because nonetheless higher furfural yields are obtained using the salts as a secondary catalyst, it is concluded that the salts influence the pentose dehydration mechanism directly. The final furfural yields obtained using oxalic acid as the primary catalyst were only slightly lower than those for similar experiments using $\mathrm{HCl}$. The most distinctive difference between the two acids is the lower reaction rate (and thus longer reaction times) when using oxalic acid. Finally, it was observed that if no acidic catalyst is used, the salts tend to catalyse a loss reaction, which is suppressed when an acid is present.
\end{abstract}

Keywords Furfural · Pentose dehydration - Oxalic acid . Seawater $\cdot$ Biorefinery

W. Hongsiri · B. Danon · W. de Jong $(\triangle)$ Process and Energy Department, Delft University of Technology, Leeghwaterstraat 44, 2628 CA Delft, The Netherlands e-mail: Wiebren.deJong@tudelft.nl

\section{Introduction}

Sustainable biorefinery processes have a high potential for commercialisation; however, the processing costs need to be minimized further for the process to become economically feasible. In view of sound sustainable biorefining development, raw materials, reaction media and catalysts are preferably derived from sustainable resources. Also, reactions are best performed under mild and environmentally favourable conditions with minimal waste formation. Waste prevention is very much preferable over treating or cleaning up [1]. Catalysts play a key role in the development of sustainable biorefinery processes for the manufacture of chemicals. The use of organic acids as catalyst for biopolysaccharide (both cellulose and hemicellulose) hydrolysis and monosaccharide dehydration (both hexose and pentose) offers a promising approach. Different organic acid catalysts (e.g. fumaric, oxalic or maleic acid) have already been investigated as substitutes for the more widely applied mineral acids (mostly $\mathrm{H}_{2} \mathrm{SO}_{4}$ or $\mathrm{HCl}$ ) [19, 29, 33, 34]. Formic acid, a byproduct of furfural degradation, has been shown to be an effective catalyst for furfural production [20]. Moreover, it can be shown to result in even slightly higher furfural yield and selectivity than phosphoric acid and sulfuric acid [40]. In this context, it has been shown that the use of an organic acid, such as fumaric, maleic or formic acid, can effectively be used instead of mineral acids [12, 19, 40].

Oxalic acid is either manufactured by the nitric acid oxidation of waste cellulosic materials or from carbon monoxide under pressure in the presence of a catalyst. The production technology has long been established [30, 31, 36]. All of the raw materials can be produced based on renewable, potentially sustainable biomass resources. Thus, the use of oxalic acid as organic acid catalyst in 
sustainable biorefineries is very attractive and has not yet been studied experimentally for the production of furfural.

Next, the use of co-catalysis, using different salts next to the acidic catalyst, has been pointed out in previous research work to improve the dehydration of lignocellulosic derivatives [15, 22, 27, 28]. Seawater offers a particularly interesting and cheap catalytic reaction medium for biorefinery processes $[14,17,21,24,33]$. Thus nonpotable water sources can be used at large scale, mainly in coastal localities, and for existing resources, such as macro algae [13].

Furfural, a hemicellulose derived platform chemical [3], promises to be a very valuable product of the lignocellulosic biomass-based biorefinery [8, 37]. It can easily be produced from biomass in a biorefinery system, and it is a precursor for many different chemicals, used for the production of bio-plastics, bioblend solvents and biofuels. The use of furfural presently is limited, which is contributed by some authors to the still inefficient production processes and the relatively low oil prices [37].

Acidic saline aqueous solutions can minimize furfural loss reactions [27, 28] as has been published previously. Although some studies investigate xylose dehydration to furfural in acidic and/or saline media, more research is needed in this area to provide a clear picture on the synergistic effects of the two catalysts. Most of the previous studies use either saline catalysts only, employ pure salts in contrast to real seawater or merely present yield studies. Recently, some papers concerning the sugar dehydration with acid and seawater have been published. Grande et al. investigated the combination of enzymes and bio-based acids for conversion of glucose into HMF in seawater [14]. Vom Stein et al. [35] used $\mathrm{FeCl}_{3} \cdot 6 \mathrm{H}_{2} \mathrm{O}, \mathrm{NaCl}$ and seawater as an additive for furfural production in a biobased biphasic system. These results provide useful and sustainable synergies for future biorefineries. However, the kinetics of the sugar dehydration have not been addressed. Knowledge on the kinetics is required for better understanding of the reaction system and for improving the reactor design.

In this study, the effects of combined catalysis of oxalic acid and seawater on the kinetics of pentose dehydration to furfural are investigated. The aim is to derive the kinetics of the formation of furfural from pentoses using oxalic acid as the primary acidic catalyst and in a natural saline medium (seawater). Information on this is missing in the literature. Therefore, first, the thermodynamic properties of the resulting reaction solution are studied. Then, experiments are presented using three different salt conditions: no salts, a $500 \mathrm{mM} \mathrm{NaCl}$ solution and seawater. The subsequent kinetic study comprises both the degradation of furfural and the dehydration of two different pentoses (xylose and arabinose). Finally, the results are compared with results from a previous study using $\mathrm{HCl}$ as the acidic catalyst. The approach followed in this study provides important data for design of reactors to be integrated into considerations of future furfural production processes.

\section{Methods and materials}

A one-litre mechanically stirred stainless steel autoclave reactor was used for the experiments. The operating pressure in the reactor was the saturation pressure of the mixture. An HPLC pump was used to introduce the reactant into the reactor. Samples were taken from the liquid phase by a sampling system making use of the pressure in the reactor. A schematic of the experimental setup is presented in Fig. 1. The reagents used in the experiments, D-xylose,
Fig. 1 Schematic of the experimental setup

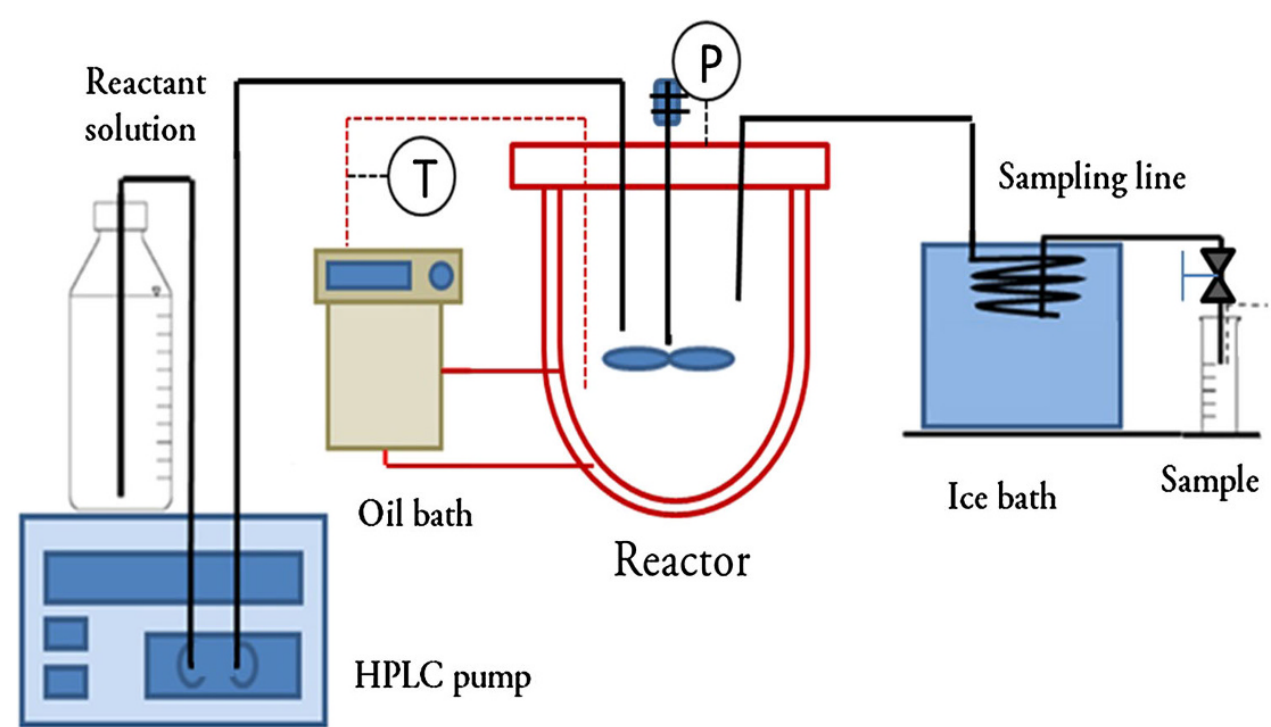


Table 1 Thermodynamic properties of reaction media with different salt conditions

\begin{tabular}{llllllll}
\hline $\begin{array}{l}\text { Oxalic acid } \\
(\mathrm{mM})\end{array}$ & $\begin{array}{l}\text { Salts } \\
(-)\end{array}$ & $\begin{array}{l}\text { Ionic strength }(I) \\
\left.(\mathrm{mol} \mathrm{kg})^{-1}\right)\end{array}$ & $\begin{array}{l}\gamma_{\mathrm{H}_{3} \mathrm{O}^{+}} \\
(-)\end{array}$ & $\begin{array}{l}\mathrm{p} K_{a 1} \\
(+)\end{array}$ & $\begin{array}{l}\mathrm{p} K_{a 2} \\
(+)\end{array}$ & $\begin{array}{l}{\left[\mathrm{H}_{3} \mathrm{O}^{+}\right]} \\
(\mathrm{mM})\end{array}$ & $\begin{array}{l}a_{\mathrm{H}_{3} \mathrm{O}^{+}} \\
(\mathrm{mM})\end{array}$ \\
\hline 50 & No salts & 0.02 & 0.80 & 1.80 & 6.01 & $2.12 \times 10^{-2}$ & $1.69 \times 10^{-2}$ \\
50 & $\mathrm{NaCl}$ & 0.48 & 0.51 & 1.35 & 5.20 & $2.74 \times 10^{-2}$ & $1.40 \times 10^{-2}$ \\
50 & Seawater & 0.54 & 0.47 & 1.32 & 5.16 & $3.05 \times 10^{-2}$ & $1.45 \times 10^{-2}$ \\
100 & No salts & 0.03 & 0.77 & 1.77 & 5.93 & $3.36 \times 10^{-2}$ & $2.57 \times 10^{-2}$ \\
100 & NaCl & 0.50 & 0.51 & 1.35 & 5.20 & $4.80 \times 10^{-2}$ & $2.44 \times 10^{-2}$ \\
100 & Seawater & 0.56 & 0.47 & 1.31 & 5.12 & $4.98 \times 10^{-2}$ & $2.36 \times 10^{-2}$ \\
\hline
\end{tabular}

L-arabinose, furfural and anhydrous oxalic acid, were obtained commercially, all with a $99 \%$ purity (SigmaAldrich). Their concentrations in the experiments were selected to be in-line with previous studies [5, 17, 26, 28] and indicate attractive economic potential [25]. The seawater was sampled from the North Sea near Scheveningen (The Netherlands) in June 2012. More details regarding the experimental procedure have been presented previously [17].

The samples were analysed using an HPLC apparatus with a Rezex RHM-Monosaccharide column, $8 \%$ cross linked $\mathrm{H}^{+}, 300 \times 7.80 \mathrm{~mm}$ (Phenomenex). A $0.005 \mathrm{~N}$ $\mathrm{H}_{2} \mathrm{SO}_{4}$ solution in demineralized water was used as the mobile phase at a flow rate of $0.6 \mathrm{ml} / \mathrm{min}$ with a column temperature of $80^{\circ} \mathrm{C}$. A Marathon XT auto-sampler (Separations) was used to improve the reproducibility. The C5-sugars were quantified by means of a Refractive Index detector (Varian Model 350), while the other products, mainly furfural, were analysed using both the Refractive Index detector and UV detector (Varian Model 310 Pro Star).

\section{Results and discussion}

\section{Thermodynamics}

In this section the thermodynamic properties of the reaction media employing the two different catalysts are presented. In order to perform these calculations, the concentrations of the ions in the $\mathrm{NaCl}$ solution and in seawater were determined using ICP-OES elemental analysis. These results have been published previously [17].

Some works have made use of the electrolytes NRTL (eNRTL) [16, 39] and Pitzer model [10] for calculating the thermodynamic properties of the aqueous electrolyte systems. In this work, by applying the eNRTL model implemented in the commercial software Aspen Plus (V-7.2), the ion activity coefficients, dissociation constants and hydronium ion concentrations have been calculated for the different reaction solutions. An advantage of the eNRTL model is the temperature dependence of ion interaction parameters which is applicable from room temperature to $270{ }^{\circ} \mathrm{C}$ [16]. The major ion concentrations of the different salt solutions were included in the model which were determined using ICP-OES elemental analysis as described above. The details of this thermodynamic property model can be found in literature $[2,4,16,23]$. The two-step dissociation of oxalic acid can be represented as follows:

$$
\begin{aligned}
& \mathrm{H}_{2} \mathrm{C}_{2} \mathrm{O}_{4}+\mathrm{H}_{2} \mathrm{O} \leftrightarrows \mathrm{HC}_{2} \mathrm{O}_{4}^{-}+\mathrm{H}_{3} \mathrm{O}^{+} \\
& \mathrm{HC}_{2} \mathrm{O}_{4}^{-}+\mathrm{H}_{2} \mathrm{O} \leftrightarrows \mathrm{C}_{2} \mathrm{O}_{4}^{2,-}+\mathrm{H}_{3} \mathrm{O}^{+}
\end{aligned}
$$

Next, using the following equation, the ionic strength is also calculated:

$I=\frac{1}{2} \sum_{i=0}^{n} m_{i} z_{i}^{2}$

where $n$ is the number of ions, $m_{i}$ is the molality of the ion $i$ and $z_{i}$ is the charge of ion $i$.

The results are presented in Table 1 and Fig. 2. It is observed that the ionic strength of the solutions increases with the salts added, as expected. However, this increase in ionic strength results in a decrease of the values of the ion activity coefficients (only the hydronium ion activity coefficient is shown). This lowers the activity of the hydronium ions and, therefore, decreases the catalytic effect of the acid. However, the results also show that the increase in ionic strength simultaneously results in an increase in the dissociation constants of the oxalic acid. This latter effect results in higher hydronium ion concentrations. In short, the addition of the salts (or the increase in the ionic strenght of the reaction solution) results in two opposite effects. In Fig. 2 it is observed that these two effects are of similar magnitude. When the hydronium ion activity is calculated (see also Fig. 2) it is observed that this variable remains fairly constant for all salt conditions.

In Fig. 3 the different effects that the addition of salts can have on the catalysis of the dehydration of pentoses are summarized. Because the above-mentioned results indicate that effect 2 and 3 in Fig. 3 cancel, it is concluded that if the salts will have any effect on the dehydration reactions, this will be through direct influences on the mechanism (effect 1 in Fig. 3). This seems to be in accordance with the 
Fig. 2 Hydronium ion concentration $\left(\left[\mathrm{H}_{3} \mathrm{O}^{+}\right]\right)$, activity coefficient $\left(\gamma_{\mathrm{H}_{3} \mathrm{O}^{+}}\right)$and activity $\left(a_{\mathrm{H}_{3} \mathrm{O}^{+}}\right)$for solutions with oxalic acid concentration of $50 \mathrm{mM}$ (a) and $100 \mathrm{mM}$ (b) for all three salt conditions at $200{ }^{\circ} \mathrm{C}$
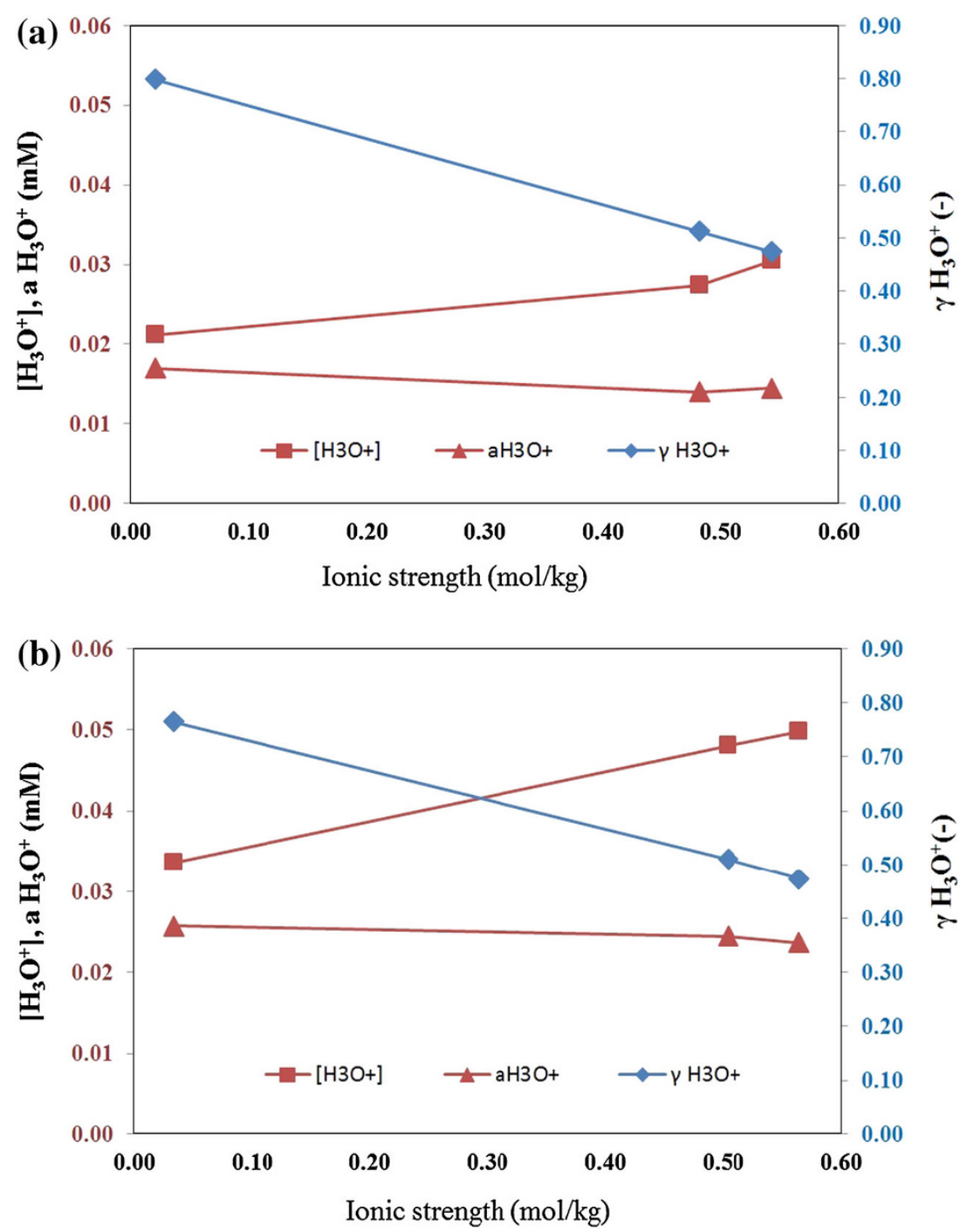

literature. Marcotullio et al. [27] propounded that anions, in particular $\mathrm{Cl}^{-}$, favor the formation of the 1,2-enediol, the first intermediate in the rate limiting reaction towards furfural, in an acidic medium. At the same time, the more polarizable halides stabilize the transitional states during subsequent dehydration steps [28]. Also the cations are reported to catalyse the pentose dehydration proportionally to their ionization potential, which increases for $\mathrm{K}^{+}, \mathrm{Na}^{+}$, $\mathrm{Ca}^{2+}, \mathrm{Mg}^{2+}$ and $\mathrm{Fe}^{3+}$ [15]; however, it is reported that this effect plays only a minor role [27].

\section{Kinetics}

The kinetics of furfural formation from xylose have been extensively studied employing different temperatures, catalysts, reactant and catalyst concentrations [7]. Generally a simple reaction scheme is assumed, as presented in Fig. 4 [11, 18, 28, 37, 41]. Most studies use first-order kinetics for both the furfural degradation $[5,15,22,26,33,37]$ and pentose dehydration reactions $[6,9,28,38]$. Moreover, the reaction scheme for arabinose dehydration is assumed to be analogous to that of xylose. A similar approach is employed in this study.

All reaction rate constants $\left(k, \min ^{-1}\right)$ are estimated by least square fitting of the concentration expressions on the experimental data. All these model equations were implemented using MATLAB. The differential equations were solved using the ode 45 function and the lsqcurvefit function was used for the fitting of the experimental data.

The molar furfural yield $Y(\%)$ is calculated using the following equation:

$$
Y=\frac{C_{f}}{C_{p, 0}} \times 100
$$

where $C_{f}$ represents the maximum furfural concentration $(\mathrm{mM})$ within the experiment and the initial pentose 


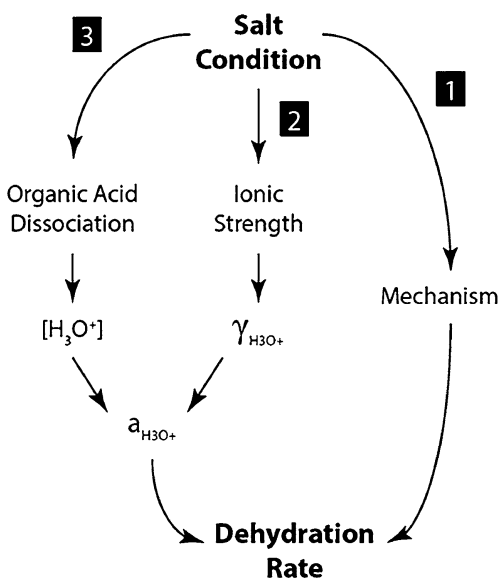

Fig. 3 Possible effects of salts on the dehydration of a pentose

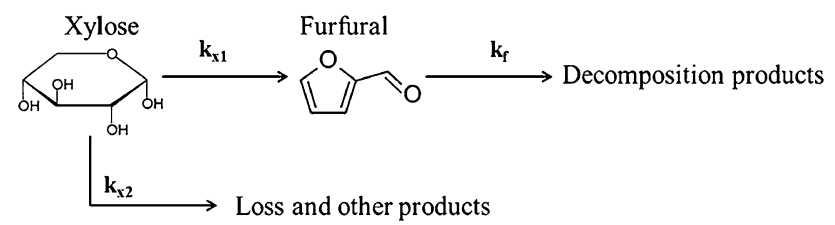

Fig. 4 The simplified reaction pathway for the dehydration of xylose to furfural

concentration $C_{p, 0}(\mathrm{mM})$ is calculated from the weight of the inserted reactant. All experiments ran for 60 min with around 15 data points per experiment.

For the degradation of furfural the activation energy $E_{a}$ $(\mathrm{kJ} / \mathrm{mol})$ and pre-exponential factor $A\left(\mathrm{~min}^{-1}\right)$ have been calculated from the values of the reaction rate constants at three different temperatures, using the Arrhenius equation for the kinetic rate constant $k$ :
$k=A \exp \left[\frac{-\mathrm{E}_{\mathrm{a}}}{\mathrm{RT}}\right]$

where $R=8.314 \mathrm{~J} /(\mathrm{mol} \mathrm{K})$ and the temperature $T$ is in $\mathrm{K}$.

In order to be able to correctly calculate the reaction rate constants for the pentose dehydration, first the rate constants for furfural degradation need to be determined. Therefore, in the following subsection, these furfural degradation rates are presented. In the subsequent subsection the kinetics of pentose dehydration using oxalic acid and different salt conditions are presented.

\section{Furfural degradation}

The kinetics of pure furfural degradation are investigated first. Experiments were performed with an initial furfural concentration of $50 \mathrm{mM}$ using $50 \mathrm{mM}$ oxalic acid at three different temperatures $\left(160,180\right.$ and $\left.200{ }^{\circ} \mathrm{C}\right)$. These experiments were all without any salt added. The results are presented in Fig. 5 and in Table 2. Also the results of comparable studies on furfural degradation (using mineral acids [17, 32, 38] and without any acidic catalyst [18]) are included for comparison purposes.

The results indicate that furfural degradation in oxalic acid is relatively slow compared to its degradation using mineral acids. It is interesting to note that the values of the activation energy decrease following an increase in the strength of the acid, as expected. However, the activation energy in water alone is close to that obtained in $\mathrm{HCl}$ (while the resulting reaction rates are the smallest). This can be explained by the fact that the degradation of furfural in water alone cannot be considered as an acid catalysed reaction, as $\mathrm{p} K_{\mathrm{w}}$ values are relatively low at high temperatures [19].
Fig. 5 Arrhenius plot for furfural degradation using different acidic catalysts

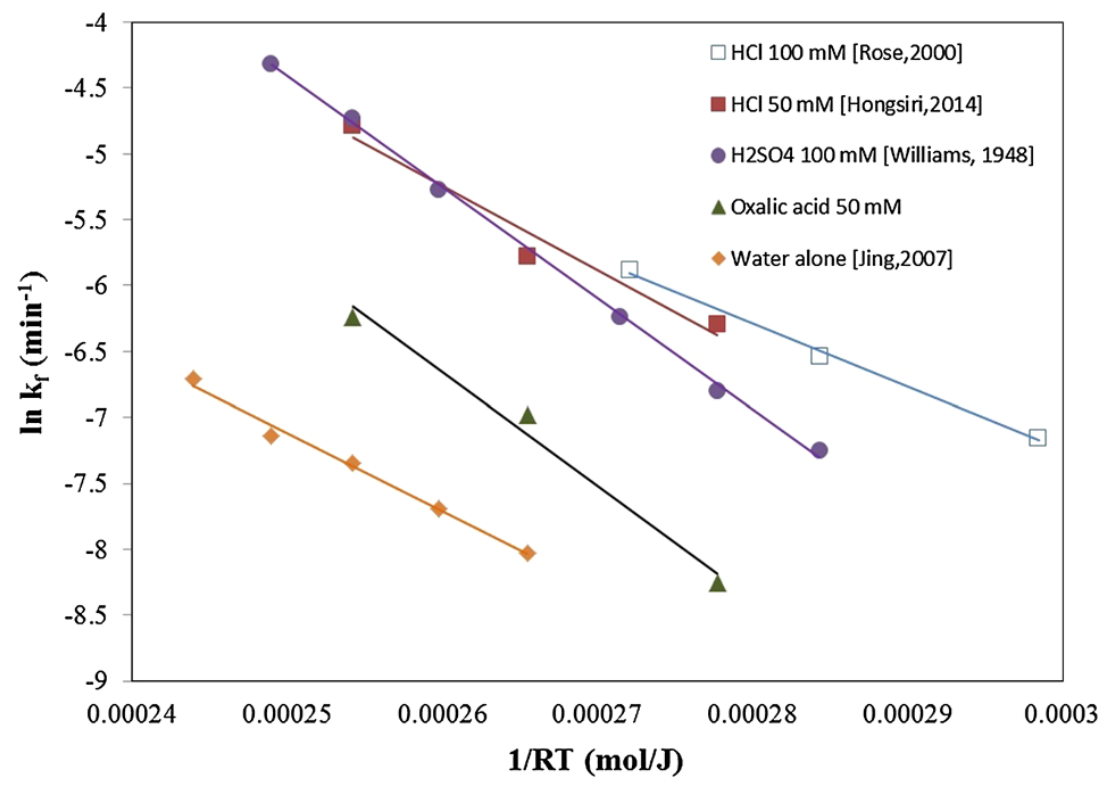


Table 2 Kinetic parameters for furfural degradation using different acidic catalysts

a This calculation is based on the experimental results of our previous study [17]

\begin{tabular}{|c|c|c|c|c|c|c|}
\hline \multicolumn{2}{|l|}{ Catalyst } & \multirow{2}{*}{$\begin{array}{l}\text { Temperature } \\
\left({ }^{\circ} \mathrm{C}\right)\end{array}$} & \multirow[t]{2}{*}{ Reactor } & \multirow{2}{*}{$\begin{array}{l}E_{a} \\
(\mathrm{~kJ} / \mathrm{mol})\end{array}$} & \multirow{2}{*}{$\begin{array}{l}A \\
\left(\min ^{-1}\right)\end{array}$} & \multirow[t]{2}{*}{ References } \\
\hline Type & $(\mathrm{mM})$ & & & & & \\
\hline $\mathrm{H}_{2} \mathrm{SO}_{4}$ & 100 & $150-210$ & Tube & 83.6 & $1.4 \times 10^{7}$ & Williams and Dunlop [38] \\
\hline $\mathrm{HCl}$ & 100 & $130-170$ & Autoclave & 48.1 & $1.3 \times 10^{3}$ & Rose et al. [32] \\
\hline $\mathrm{HCl}$ & 50 & $160-200$ & Autoclave & 63.9 & $2.0 \times 10^{3}$ & This study ${ }^{a}$ \\
\hline $\mathrm{H}_{2} \mathrm{C}_{2} \mathrm{O}_{4}$ & 50 & $160-200$ & Autoclave & 86.3 & $7.1 \times 10^{6}$ & This study \\
\hline Water & - & $180-220$ & Autoclave & 58.8 & $1.2 \times 10^{5}$ & Jing and Lü [18] \\
\hline
\end{tabular}

It was shown before that the furfural degradation rates (using $\mathrm{HCl}$ as the acidic catalyst) were lower when salts are present [17]. However, since these rates using oxalic acid are smaller by a factor of 10 , it is chosen here to use the same values for all different saline conditions. The value of $k_{f}$ that will be used in the calculation of the pentose dehydration kinetics at $200{ }^{\circ} \mathrm{C}$ in the next section is $2.0 \times 10^{-3} \mathrm{~min}^{-1}$.
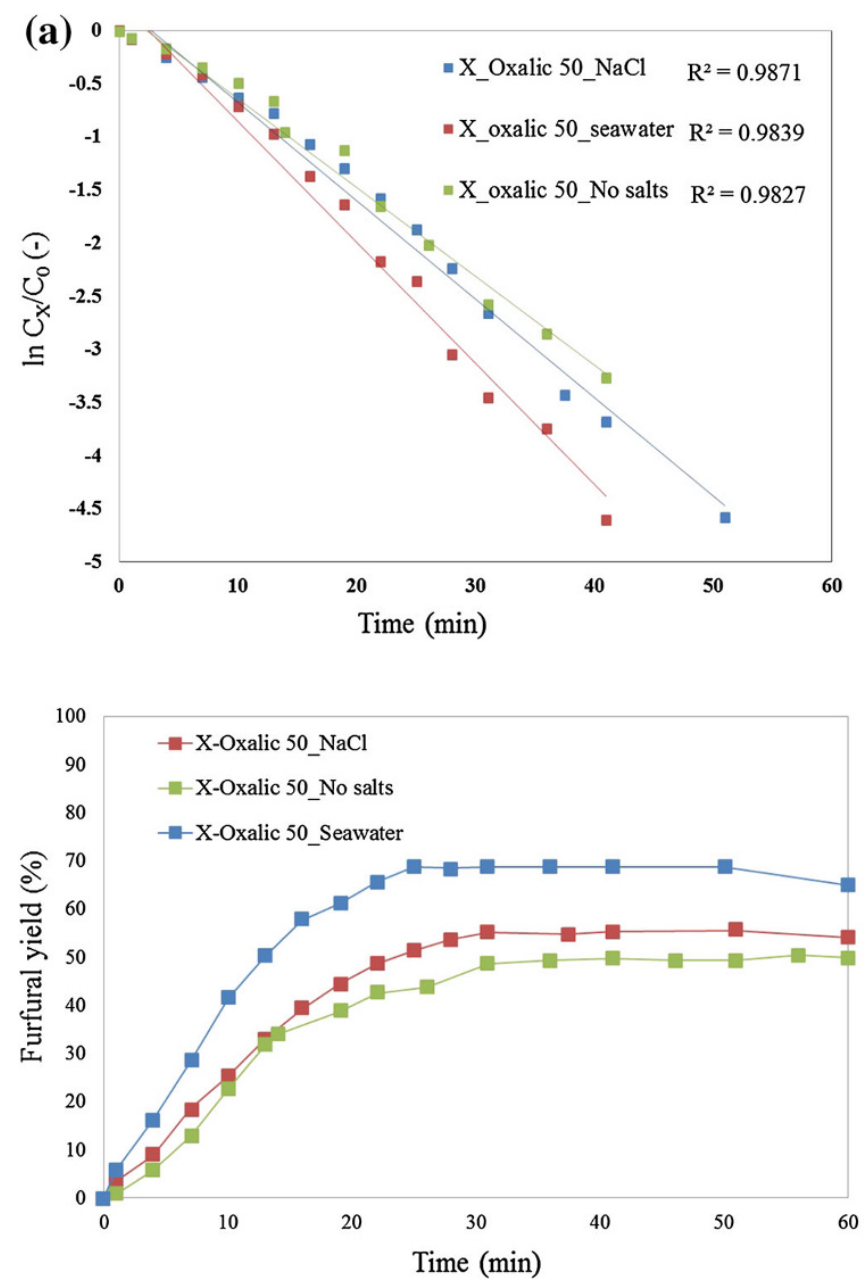

\section{Pentose dehydration}

The pentose degradation experiments were performed with an initial pentose concentration of $50 \mathrm{mM}$ and oxalic acid concentrations of 50 and $100 \mathrm{mM}$. Three different salt conditions were investigated: no salts, a $500 \mathrm{mM} \mathrm{NaCl}$ solution and seawater, all at $200{ }^{\circ} \mathrm{C}$.
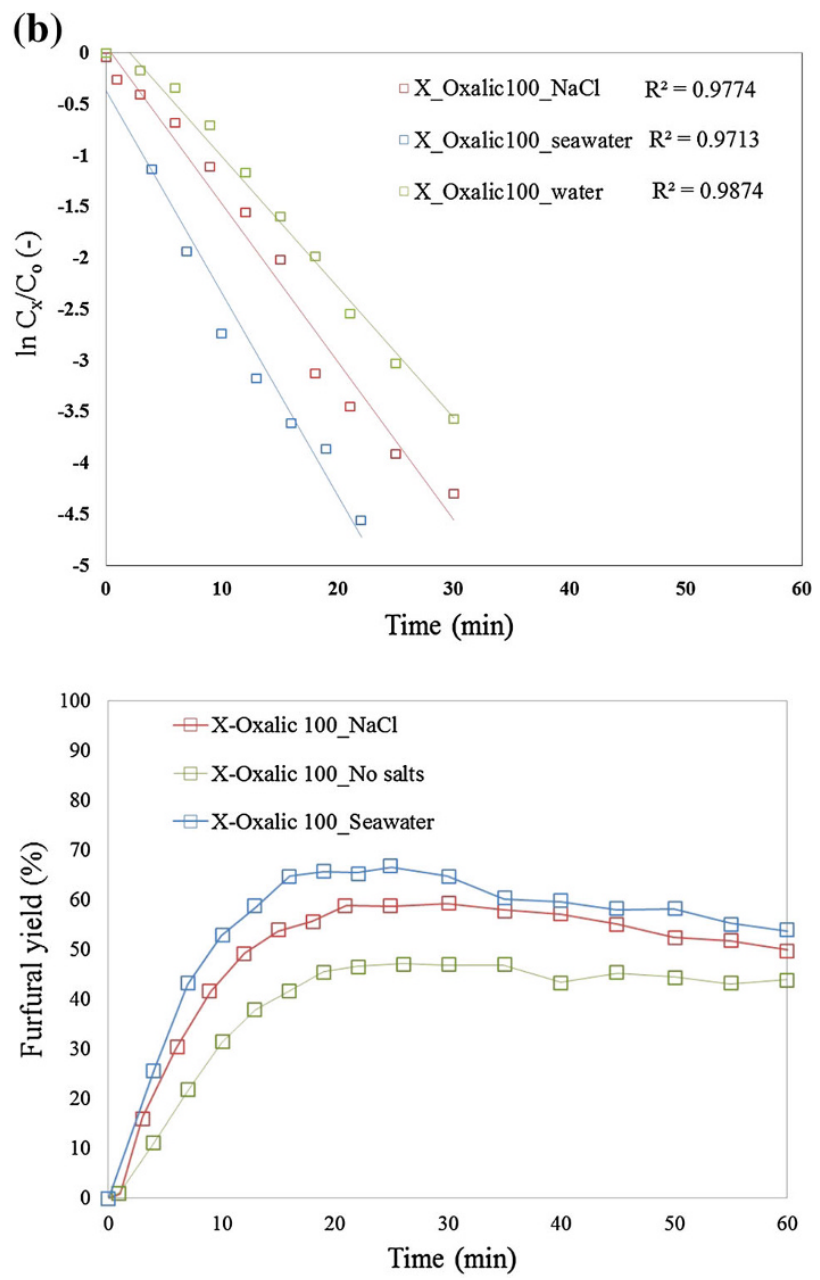

Fig. 6 Xylose degradation (upper row) and furfural yields (lower row) in $50 \mathrm{mM}$ (a) and $100 \mathrm{mM}$ (b) oxalic acid at $200{ }^{\circ} \mathrm{C}$ with three different salt conditions. $X$ xylose, Oxalic oxalic acid 
Table 3 Estimated kinetic rate parameters for xylose dehydration at $200{ }^{\circ} \mathrm{C}$

\begin{tabular}{|c|c|c|c|c|c|c|}
\hline \multicolumn{2}{|l|}{ Catalyst } & \multirow[t]{2}{*}{ Salts } & \multicolumn{3}{|c|}{ Rate constant $\left(\times 10^{-3}\right)$} & \multirow{2}{*}{$\begin{array}{l}Y \\
(\%)\end{array}$} \\
\hline Type & $(\mathrm{mM})$ & & $\begin{array}{l}k_{x 1} \\
\left(\min ^{-1}\right)\end{array}$ & $\begin{array}{l}k_{x 2} \\
\left(\min ^{-1}\right)\end{array}$ & $k_{x 1} / k_{x 2}$ & \\
\hline Oxalic acid & 50 & No salts & 34.0 & 21.3 & 1.60 & 50.5 \\
\hline Oxalic acid & 50 & $\mathrm{NaCl}$ & 45.1 & 23.2 & 1.94 & 59.3 \\
\hline Oxalic acid & 50 & Seawater & 62.8 & 18.5 & 3.39 & 68.8 \\
\hline Oxalic acid & 100 & No salts & 51.0 & 57.0 & 0.89 & 47.2 \\
\hline Oxalic acid & 100 & $\mathrm{NaCl}$ & 76.7 & 75.2 & 1.02 & 59. \\
\hline Oxalic acid & 100 & Seawater & 150.1 & 74.3 & 2.02 & 66. \\
\hline Formic acid [20] & $\mathrm{pH} 1.53$ & No salts & 150.0 & 30.0 & 5.00 & 60. \\
\hline $\mathrm{H}_{2} \mathrm{SO}_{4}[27]$ & 50 & No salts & 195.6 & 81.6 & 2.40 & 61. \\
\hline $\mathrm{HCl}[17]$ & 50 & No salts & 123.1 & 73.7 & 1.67 & 52.8 \\
\hline $\mathrm{HCl}[17]$ & 50 & $\mathrm{NaCl}$ & 226.3 & 111.3 & 2.03 & 64.3 \\
\hline $\mathrm{HCl}[17]$ & 50 & Seawater & 268.8 & 97.4 & 2.76 & 71.7 \\
\hline $\mathrm{HCl}$ [27] & 50 & No salts & 223.8 & 56.4 & 3.97 & 68.7 \\
\hline $\mathrm{HCl}[27]$ & 50 & $\mathrm{NaCl}$ & 317.0 & 70.2 & 4.51 & 72.8 \\
\hline Water [18] & - & No salts & 11.9 & 12.3 & 0.96 & 40.0 \\
\hline Water [17] & - & No salts & 17.2 & 13.2 & 1.30 & 51.5 \\
\hline Water [17] & - & $\mathrm{NaCl}$ & 25.0 & 21.3 & 1.17 & 46. \\
\hline Water [17] & - & Seawater & 47.6 & 61.7 & 0.77 & 44 \\
\hline
\end{tabular}
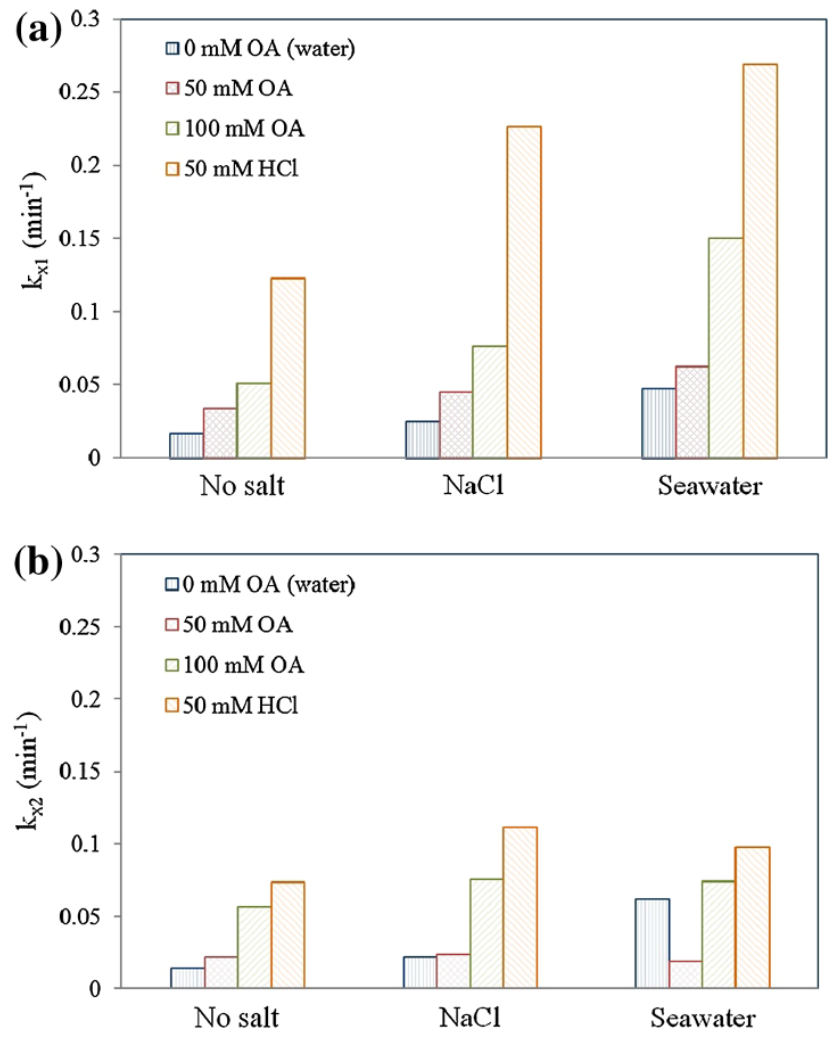

Fig. 7 Kinetic rate constants of xylose dehydration under different acid and salt conditions at $200^{\circ} \mathrm{C}$. a $k_{x 1}$, b $k_{x 2}$. $O A$ oxalic acid
Table 4 Estimated kinetic rate parameters for arabinose dehydration at $200{ }^{\circ} \mathrm{C}$

\begin{tabular}{|c|c|c|c|c|c|c|}
\hline \multicolumn{2}{|l|}{ Catalyst } & \multirow[t]{2}{*}{ Salts } & \multicolumn{3}{|c|}{ Rate constant $\left(\times 10^{-3}\right)$} & \multirow{2}{*}{$\begin{array}{l}Y \\
(\%)\end{array}$} \\
\hline Type & $(\mathrm{mM})$ & & $\begin{array}{l}k_{a 1} \\
\left(\min ^{-1}\right)\end{array}$ & $\begin{array}{l}k_{a 2} \\
\left(\min ^{-1}\right)\end{array}$ & $k_{a 1} / k_{a 2}$ & \\
\hline Oxalic acid & 50 & No salts & 16.7 & 33.9 & 0.49 & 24.5 \\
\hline Oxalic acid & 50 & $\mathrm{NaCl}$ & 31.8 & 39.0 & 0.82 & 44.7 \\
\hline Oxalic acid & 50 & Seawater & 45.7 & 44.3 & 1.03 & 48.2 \\
\hline Oxalic acid & 100 & No salts & 29.3 & 46.7 & 0.63 & 29.4 \\
\hline Oxalic acid & 100 & $\mathrm{NaCl}$ & 50.9 & 31.2 & 1.63 & 52.0 \\
\hline Oxalic acid & 100 & Seawater & 49.6 & 31.6 & 1.57 & 51.9 \\
\hline $\mathrm{HCl}[17]$ & 50 & No salts & 49.9 & 50.5 & 0.99 & 34.5 \\
\hline $\mathrm{HCl}[17]$ & 50 & $\mathrm{NaCl}$ & 106.6 & 90.1 & 1.18 & 49.1 \\
\hline $\mathrm{HCl}[17]$ & 50 & Seawater & 115.0 & 88.8 & 1.30 & 53.9 \\
\hline Water [17] & - & No salts & 11.2 & 27.1 & 0.41 & 24.1 \\
\hline Water [17] & - & $\mathrm{NaCl}$ & 23.4 & 22.1 & 1.06 & 27.0 \\
\hline Water [17] & - & Seawater & 42.3 & 60.6 & 0.70 & 26.2 \\
\hline
\end{tabular}

In the upper row of Fig. 6 the symbols represent the experimental results while the lines represent the kinetic model for the dehydration rate of xylose. This dehydration rate is defined as $\left(k_{x 1}+k_{x 2}\right)$. The molar furfural yields are presented in the lower row of Fig. 6.

First, the xylose dehydration rate is discussed. It is observed that the dehydration rate of xylose is dependent on both catalysts; an increase in acid concentration and the addition of salts result in increased dehydration rates. However, the increase in the rate due to the increase in acid concentration is larger than that due to the addition of the salts.

Next, regarding the furfural yields, the effects of the two catalysts are different. The addition of salts results in a distinct increase of the furfural yield, for both acid concentrations. However, the maximum furfural yields are comparable for the two different acid concentrations.

These observations are confirmed by the estimated values for the kinetic rate parameters, see Table 3. Both the values of $k_{x 1}$ and $k_{x 2}$ increase significantly due to the doubling of the oxalic acid concentration (explaining the relatively high increase in the dehydration rate), while for the different salt conditions only such a distinct increase is observed for $k_{x 1}$. This can be observed more clearly in Fig. 7 where the two reaction rates of xylose are presented graphically for the different salt conditions. Comparing the trend in the bars for any of the acid cases clearly shows that where $k_{x 1}$ increases with the addition of the salts, $k_{x 2}$ remains fairly constant. The trends of 50 and $100 \mathrm{mM}$ oxalic acid, however, are similar in shape; the main difference is the fact that both $k$ values are higher when using $100 \mathrm{mM}$ oxalic acid. In other words, the addition of the salts selectively favours $k_{x 1}$, the reaction towards furfural, 

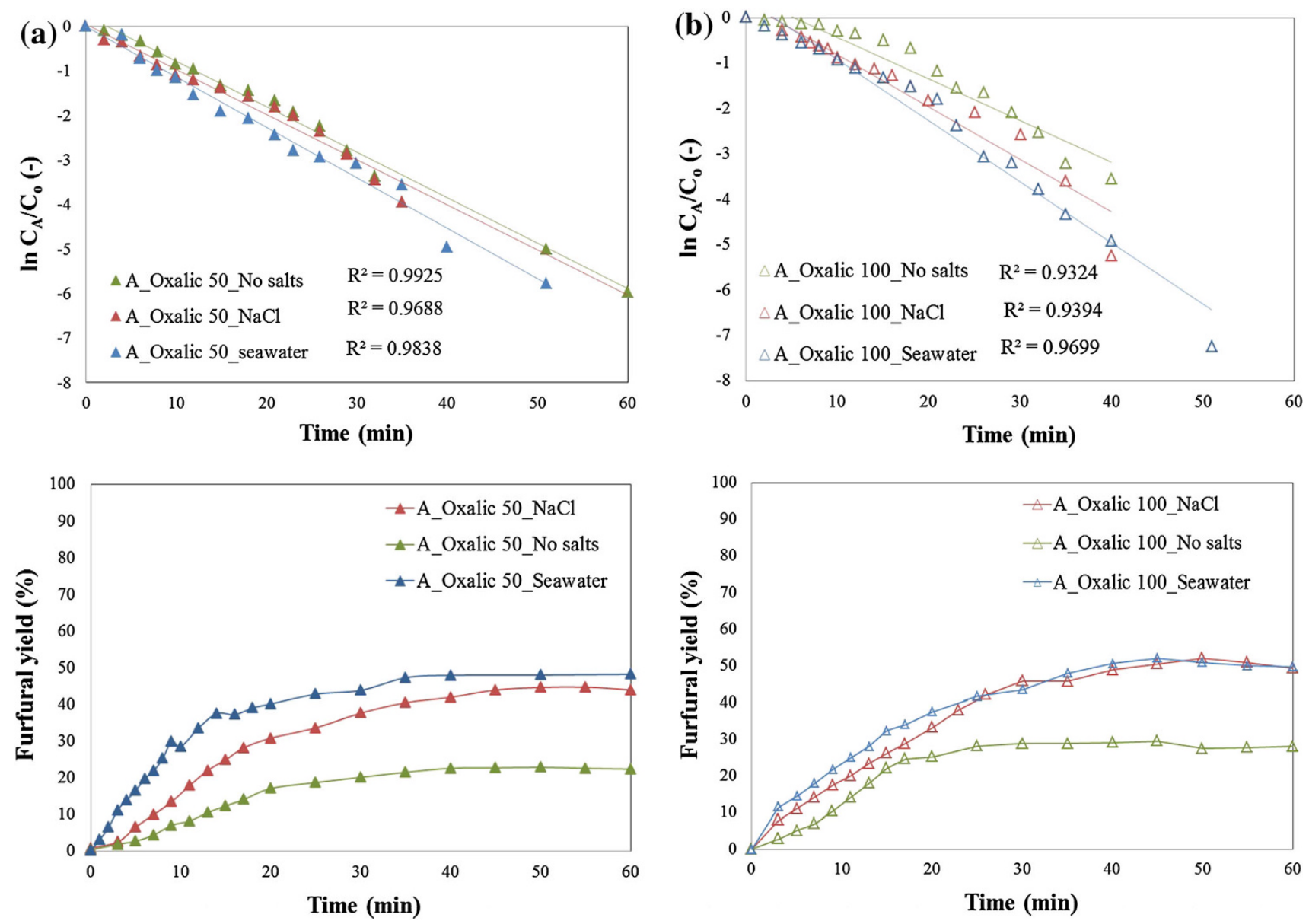

Fig. 8 Arabinose degradation (upper row) and furfural yields (lower row) in $50 \mathrm{mM}$ (a) and $100 \mathrm{mM}$ (b) oxalic acid at $200{ }^{\circ} \mathrm{C}$ with three different salt conditions. A arabinose, Oxalic oxalic acid

while an increase in the acid concentration favours both reactions more or less equally.

These results are in accordance with previous observations for these reactions using $\mathrm{HCl}$ as the acidic catalyst [17]. Moreover, the final furfural yields are comparable for using either a mineral acid or an organic acid combined with salts, see Table 3 . Only the reaction rates were significantly lower in the latter case.

Thus, it is concluded that oxalic acid catalyses both the reactions towards furfural and towards loss products equally, while the presence of the salts (and especially the combined ions of seawater) catalyses the reaction towards furfural more selectively. These conclusions confirm the hypothesis that the salts have a direct influence on the mechanism, without interfering significantly with the acidic catalysis. Moreover, if seawater is used as the reaction medium, the mineral acids can be replaced by organic acids without a loss of final yield.

In Fig. 8 and Table 4 the results for arabinose dehydration are presented. The results indicate that salts have a significant effect on arabinose dehydration and the subsequent furfural formation. The trends for the two different oxalic acid concentrations are similar, i.e., both $k$ values are higher when using $100 \mathrm{mM}$ oxalic acid. Analogue trends observed for xylose are also observed for arabinose. However, the main difference between the two pentoses is that the arabinose reactions are generally slower and the furfural yields lower. Also, the increase in the oxalic acid concentration has a distinct smaller effect on the reaction rates of arabinose, compared to the increase in the xylose reaction rates. However, it is observed again that the furfural yields increase with the addition of the salts, especially in case of seawater.

There is one final remarkable observation in Fig.7. This is the fact that, when no acid is present, the $k_{x 2}$ also increases with the addition of the salts. In none of the experiments with an acidic catalyst this is the case. This behaviour has been reported before; Liu et al. showed that the loss reactions during the dehydration of xylose and xylotriose increase with the addition of inorganic salts as the sole catalyst [22]. It seems that the salts catalyse a specific loss reaction, which is suppressed in the presence 
of an acid. Further dedicated research is required for identification of this reaction.

\section{Conclusions}

In this study the effects of the combined catalysis of oxalic acid and salts on the dehydration of pentoses to furfural have been investigated. From a thermodynamic point of view, the presence of the salts resulted in an increase of the hydronium ion concentration and a decrease of the hydronium ion activity coefficient. These two effects of the salts on the acidic catalyst were of the same order of magnitude and thus compensated each other. Next, the catalytic effects of the two catalysts on the reaction rate constants have been assessed. First-order kinetic models have been applied for this purpose. Because the degradation rates of furfural, when using oxalic acid, are very low, the same degradation rate value was used for the different salt conditions. It turned out that an increase in the acid concentration resulted in higher dehydration rates by increasing both the reaction rates towards furfural and loss products. The addition of the salts, however, resulted selectively in higher reaction rates towards furfural, thus also increasing the final selectivity. This confirmed the conclusions of the thermodynamic analysis where it was observed that the salts influence the dehydration mechanism directly. However, when there is no acid in the reaction mixture, the salts also catalyse an unknown loss reaction (a side reaction). Finally, it was observed that using $\mathrm{HCl}$ higher reaction rates were observed compared to using oxalic acid, while comparable furfural yields were obtained for the two acids.

Acknowledgments Kasetsart University in Thailand is kindly acknowledged for co-funding this research. Michel van den Brink is thanked for performing the ICP-OES analysis.

Open Access This article is distributed under the terms of the Creative Commons Attribution License which permits any use, distribution, and reproduction in any medium, provided the original author(s) and the source are credited.

\section{References}

1. Anastas, P.T., Zimmerman, J.B.: Peer reviewed: design through the 12 principles of green engineering. Environ. Sci. Technol. 37(5), 94A-101A (2003)

2. Aspentech: Aspen Physical Property System: Physical Property Model, Aspen Technology, Inc. Version Number: V7.2. https:// www.aspentech.com

3. Bozell, J.J., Petersen, G.R.: Technology development for the production of biobased products from biorefinery carbohydrates-the US department of energy's "top 10" revisited. Green Chem. 12(4), 539-554 (2010)
4. Chen, C.C., Song, Y.: Generalized electrolyte-nrtl model for mixed-solvent electrolyte systems. AIChE J. 50(8), 1928-1941 (2004)

5. Danon, B., van der Aa, L., de Jong, W.: Furfural degradation in a dilute acidic and saline solution in the presence of glucose. Carbohydr. Res. 375, 145-152 (2013)

6. Danon, B., Hongsiri, W., van der Aa, L., de Jong, W.: Kinetic study on homogeneously catalyzed xylose dehydration to furfural in the presence of arabinose and glucose. Biomass Bioenerg 66 , 364-370 (2014)

7. Danon, B., Marcotullio, G., de Jong, W.: Mechanistic and kinetic aspects of pentose dehydration towards furfural in aqueous media employing homogeneous catalysis. Green Chem. 16, 39-54 (2014)

8. De Jong, W., Marcotullio, G.: Overview of biorefineries based on co-production of furfural, existing concepts and novel developments. Int. J. Chem. React. Eng. 8(1), Article ID A69 (2010)

9. Root, D.F., Saeman, J.F., Harris, J.F., Neill, W.K.: Kinetics of the acid-catalyzed conversion of xylose to furfural. For. Prod. J. 9(5), 158-165 (1959)

10. Dickson, A.G., Wesolowski, D.J., Palmer, D.A., Mesmer, R.E.: Dissociation constant of bisulfate ion in aqueous sodium chloride solutions to $250{ }^{\circ} \mathrm{C}$. J. Phys. Chem. 94(20), 7978-7985 (1990)

11. Dunlop, A.: Furfural formation and behavior. Ind. Eng. Chem. 40(2), 204-209 (1948)

12. Fischmeister, C., Bruneau, C., De Oliveria Vigier, K., Jérôme, F.: Catalytic conversion of biosourced raw materials: homogeneous catalysis. In: Aresta, M., Dibenedetto, A., Dumeignil, F. (eds.) Biorefinery: from biomass to chemicals and fuels, Chap 10 , p. 234. Walter de Gruyter, Berlin (2012)

13. Foley, P.M., Beach, E.S., Zimmerman, J.B.: Algae as a source of renewable chemicals: opportunities and challenges. Green Chem. 13(6), 1399-1405 (2011)

14. Grande, P.M., Bergs, C., Domínguez de María, P.: Chemoenzymatic conversion of glucose into 5-hydroxymethylfurfural in seawater. ChemSusChem 5(7), 1203-1206 (2012)

15. Gravitis, J., Vedernikov, N., Zandersons, J., Kokorevics, A.: Furfural and levoglucosan production from deciduous wood and agricultural wastes. In: ACS Symposium Series, vol. 784, pp. 110-122. American Chemical Society Publications, Washington, DC (2001)

16. Haghtalab, A., Papangelakis, V.G., Zhu, X.: The electrolyte nrtl model and speciation approach as applied to multicomponent aqueous solutions of $\mathrm{H}_{2} \mathrm{SO}_{4}, \mathrm{Fe}_{2}\left(\mathrm{SO}_{4}\right)_{3}, \mathrm{MgSO}_{4}$ and $\mathrm{Al}_{2}\left(\mathrm{SO}_{4}\right)_{3}$ at $230-270{ }^{\circ} \mathrm{C}$. Fluid Phase Equilib. 220(2), 199-209 (2004)

17. Hongsiri, W., Danon, B., Jong, W.: Kinetic study on the dilute acidic dehydration of pentoses toward furfural in seawater. Ind. Eng. Chem. Res. 53(13), 5455-5463 (2014)

18. Jing, Q., Lü, X.: Kinetics of non-catalyzed decomposition of Dxylose in high temperature liquid water. Chin. J. Chem. Eng. 15(5), 666-669 (2007)

19. Kootstra, A.M.J., Mosier, N.S., Scott, E.L., Beeftink, H.H., Sanders, J.P.: Differential effects of mineral and organic acids on the kinetics of arabinose degradation under lignocellulose pretreatment conditions. Biochem. Eng. J. 43(1), 92-97 (2009)

20. Lamminpää, K., Ahola, J., Tanskanen, J.: Kinetics of xylose dehydration into furfural in formic acid. Ind. Eng. Chem. Res. 51(18), 6297-6303 (2012)

21. Lin, C.S., Luque, R., Clark, J.H., Webb, C., Du, C.: A seawaterbased biorefining strategy for fermentative production and chemical transformations of succinic acid. Energy Environ. Sci. 4(4), 1471-1479 (2011)

22. Liu, C., Wyman, C.E.: The enhancement of xylose monomer and xylotriose degradation by inorganic salts in aqueous solutions at $180{ }^{\circ} \mathrm{C}$. Carbohydr. Res. 341(15), 2550-2556 (2006) 
23. Malahias, L., Popovych, O.: Activity coefficients and transfer free energies of potassium chloride in methanol-water solvents at $25^{\circ}$ C. J. Chem. Eng. Data 27(2), 105-109 (1982)

24. Mao, L., Zhang, L., Gao, N., Li, A.: Seawater-based furfural production via corncob hydrolysis catalyzed by $\mathrm{FeCl}_{3}$ in acetic acid steam. Green Chem. 15(3), 727-737 (2013)

25. Marcotullio, G.: The Chemistry and Technology of Furfural Production in Modern Lignocellulose-Feedstock Biorefineries. Delft University of Technology, Delft (2011)

26. Marcotullio, G., Cardoso, M.A.T., De Jong, W., Verkooijen, A.H.: Bioenergy II: furfural destruction kinetics during sulphuric acid-catalyzed production from biomass. Int. J. Chem. React. Eng. 7(1), Article ID A67 (2009)

27. Marcotullio, G., De Jong, W.: Chloride ions enhance furfural formation from $\mathrm{D}$-xylose in dilute aqueous acidic solutions. Green Chem. 12(10), 1739-1746 (2010)

28. Marcotullio, G., De Jong, W.: Furfural formation from D-xylose: the use of different halides in dilute aqueous acidic solutions allows for exceptionally high yields. Carbohydr. Res. 346(11), 1291-1293 (2011)

29. Mosier, N.S., Ladisch, C.M., Ladisch, M.R.: Characterization of acid catalytic domains for cellulose hydrolysis and glucose degradation. Biotechnol. Bioeng. 79(6), 610-618 (2002)

30. Othmer, K.: Encyclopedia of chemical technology, 2nd edn, vol. 13, p 13. Wiley, New York (1967)

31. Riemenschneider, W., Tanifuji, M.: Ullmann's Encyclopedia of Industrial Chemistry, vol. 784, pp. 529-541. Wiley-VCH (2012)

32. Rose, I.C., Epstein, N., Watkinson, A.P.: Acid-catalyzed 2-furaldehyde (furfural) decomposition kinetics. Ind. Eng. Chem. Res. 39(3), 843-845 (2000)

33. vom Stein, T., Grande, P., Sibilla, F., Commandeur, U., Fischer, R., Leitner, W., Domínguez de María, P.: Salt-assisted organic- acid-catalyzed depolymerization of cellulose. Green Chem. 12(10), 1844-1849 (2010)

34. vom Stein, T., Grande, P.M., Kayser, H., Sibilla, F., Leitner, W.: rom biomass to feedstock: one-step fractionation of lignocellulose components by the selective organic acid-catalyzed depolymerization of hemicellulose in a biphasic system. Green Chem. 13, 1772-1777 (2011)

35. vom Stein, T., Leitner, P.M., Leitner, W., Domínguez de María, P.: Iron-catalyzed furfural production in biobased biphasic systems: from pure sugars to direct use of crude xylose effluents as feedstock. ChemSusChem 4(11), 1592-1594 (2011)

36. Sullivan, J.M., Williard, J.W., White, D.L., Kim, Y.K.: Production of oxalic acid via the nitric acid oxidation of hardwood (red oak) sawdust. Ind. Eng. Chem. Prod. Res. Dev. 22(4), 699-709 (1983)

37. Weingarten, R., Cho, J., Conner Jr, W.C., Huber, G.W.: Kinetics of furfural production by dehydration of xylose in a biphasic reactor with microwave heating. Green Chem. 12(8), 1423-1429 (2010)

38. Williams, D., Dunlop, A.: Kinetics of furfural destruction in acidic aqueous media. Ind. Eng. Chem. 40(2), 239-241 (1948)

39. Yan, Y., Chen, C.C.: Thermodynamic modeling of $\mathrm{CO}_{2}$ solubility in aqueous solutions of $\mathrm{NaCl}$ and $\mathrm{Na}_{2} \mathrm{SO}_{4}$. J. Supercrit. Fluids 55(2), 623-634 (2010)

40. Yang, W., Li, P., Bo, D., Chang, H.: The optimization of formic acid hydrolysis of xylose in furfural production. Carbohydr. Res. 357, 53-61 (2012)

41. Zeitsch, K.J.: The Chemistry and Technology of Furfural and Its Many By-products, Sugar Series, vol. 13. Elsevier, Amsterdam (2000) 